\title{
VIDA COTIDIANA, APOYO SOCIAL Y EXPERIENCIA DE SOLEDAD EN PERSONAS MAYORES DEL ÁREA METROPOLITANA DE BUENOS AIRES, ARGENTINA
}

Paula Pochintesta ${ }^{1}$

\section{La viudez ¿transición o punto de inflexión? en el envejecimiento}

Este trabajo se propone analizar en qué consiste el ajuste a la pérdida del cónyuge percibida por varones y mujeres de 65 y más años, residentes en el Área Metropolitana de Buenos Aires, Argentina. Se trata de un estudio cualitativo y retrospectivo que busca, a partir de la reconstrucción de las trayectorias biográficas, dimensionar qué lugar tiene la viudez como un evento clave en el proceso de envejecimiento. Tanto desde el punto de vista teórico como metodológico el trabajo se inscribe en la perspectiva del curso de vida.

La viudez es mucho más frecuente en la vejez que en cualquier otro momento de la vida. No obstante ello, a nivel social, no existen programas o políticas que preparen a las personas mayores para afrontar los cambios asociados a la muerte del cónyuge. Lo cierto que es que las personas no saben si perderán o no a su pareja, pero la posibilidad de enviudar en la vejez, es en cierta medida “esperable” según los parámetros demográficos.

Argentina se caracteriza por bajas tasas de fecundidad y mortalidad y un aumento en la esperanza de vida que da cuenta de una transición demográfica ${ }^{2}$ (Gragnolati et al., 2014; Guzmán et al., 2006). De modo que aumenta la población envejecida y disminuye el crecimiento poblacional (Censo Nacional de Población, Hogares y Viviendas, INDEC 2010) ${ }^{3}$.

\footnotetext{
${ }^{1}$ Facultad Latinoamericana de Ciencias Sociales (FLACSO-Argentina).

2 Esta transición ocurre también en el plano epidemiológico reemplazando las enfermedades infectocontagiosas por enfermedades crónico-degenerativas como patrones causales de mortalidad.

${ }^{3}$ El índice que se emplea para determinar el envejecimiento de una población (desde la gerontología) es aquel que estima la cantidad de personas de 60 y más años. De este modo, se considera que la estructura poblacional está envejecida si la población de 60 años o más es superior al 7\%. En Argentina ese porcentaje corresponde al 10,2 \% según los datos de último Censo (2010).
} 
En Argentina, los datos sobre la situación conyugal ${ }^{4}$ son esclarecedores respecto a la probabilidad de enviudar conforme se avanza en edad. Según los resultados del último censo el porcentaje de personas viudas alcanza el 6,5\% del total de la población. Si analizamos la proporción de viudas y viudos en el grupo de las personas mayores observamos que siete de cada diez varones de 65 a 84 años convive en pareja, mientras que sólo cuatro de cada diez mujeres lo hace. Esta tendencia se incrementa en el grupo de 85 y más años. Uno de los factores que se asocia a este fenómeno radica en la mayor longevidad femenina ${ }^{5}$ dando lugar a que la viudez afecte más tempranamente y en mayor proporción a las mujeres.

Según la Encuesta realizada en Argentina sobre Calidad de Vida en Adultos Mayores (2012) entre la población de 60 años y más las viudas alcanzan el 38,6\% mientras que el porcentaje de viudos es del 10,7\%. La conjunción de dos factores: a) diferencia de edad entre cónyuges y b) diferencia en la expectativa de vida entre varones y mujeres permite comprender el incremento de la viudez femenina.

Estos datos aportan un panorama para repensar cómo es y será la incidencia del fenómeno de la viudez en el envejecimiento. La pérdida del cónyuge se presenta como una transición "típica” entre la tercera y cuarta edad que implica, por un lado, una transformación del sí mismo y, por otro, una transición relacional (Caradec, 1998).

La muerte del cónyuge se convierte en un fenómeno disruptivo cuyas principales consecuencias suponen tanto el incremento del sentimiento de soledad, como una mayor vulnerabilidad social y económica (Delbès y Gaymu, 2002). La forma de transitar la viudez se encuentra además afectada por los cambios en las dinámicas familiares (Sánchez Vera, 2009).

Atravesar la etapa del duelo es crucial porque en esos momentos las personas se sienten más vulnerables. Es así que los riesgos de contraer enfermedades se incrementan durante los dos años posteriores a la pérdida (Hagedoorn et al., 2006).

El impacto que produce la muerte del cónyuge es diferencial de acuerdo a la edad, el género, el nivel socio económico, el estado de salud y la percepción de las redes de apoyo social con las que cuenta el viudo/a. Muchas investigaciones se han concentrado en las viudas debido a su mayor proporción entre la población envejecida (Del Pozo y Thumala Dockendorff, 2016; Doblas et al., 2014; Gillen y Kim, 2009; Moorman, 2006;

\footnotetext{
${ }^{4}$ La situación conyugal se define respecto a la convivencia en pareja de las personas de 14 años y más, sea ésta de hecho o de derecho (Censo Nacional del Población, Hogares y Viviendas, INDEC 2010).

${ }^{5}$ Una mayor esperanza de vida en las mujeres dio origen a la "feminización del envejecimiento".
} 
Beal, 2006). La viudez femenina se asocia a la disminución de ingresos, el aumento de la mortalidad, el incremento del riesgo de suicidio y el padecimiento de enfermedades como la ansiedad y la depresión (Lopata, 1973).

Los viudos suelen buscar pareja más a menudo que las viudas y, con frecuencia, se unen a mujeres menores que ellos. Si la participación en la organización de las tareas domésticas era mínima o inexistente, la muerte del cónyuge resultará muy estresante (Arber y Ginn, 1996).

La repercusión de la viudez en las redes sociales evidencia que existe una merma en la red familiar secundaria ${ }^{6}$. Las viudas presentan pérdidas menores en la red familiar mientras que los viudos mantienen una importante red de amigos con quienes intensifican sus relaciones (Ayuso, 2012; Berger, 2009; Ha et al., 2006). Las mujeres viudas confían en sus hermanas, hijas e hijos mayores con quienes refuerzan sus vínculos (Utz et al., 2002).

La pérdida de la pareja puede ser también una oportunidad de crecimiento personal y aprendizaje, por ejemplo, en relación al mantenimiento y a la administración financiera del hogar (Carr, 2004). En esta línea, un estudio realizado con mujeres viudas en Chile, muestra cómo la pérdida del cónyuge es vivida en varias ocasiones como una “liberación”. Así, este hito biográfico incrementa la autonomía de las viudas y su capacidad de decisión (Osorio-Parraguez, 2013).

Ahora bien, para analizar el fenómeno de la viudez en el envejecimiento es fundamental comprender que a medida que el tiempo pasa, los cursos de vida se complejizan y se vuelven más heterogéneos. Es por ello que, para contemplar la diversidad que define a la vejez, resultó útil apelar a los principios que estructuran el paradigma del curso de vida. Este enfoque permite pensar las diferencias, tanto entre las cohortes que se mueven en el tiempo histórico, como al interior de las mismas porque pone en juego el impacto en las biografías de los eventos vitales y, a la vez, de los sucesos sociohistóricos (Hareven, 1996). Así, el envejecimiento implica tanto la interacción de factores biológicos, psicológicos como sociales e históricos a partir de los cuales los sujetos construyen su biografía desde una posición activa (Lalive D’epinay, et al., 2011).

\footnotetext{
${ }^{6}$ La red familiar primaria está integrada por padre, madre, hermanos e hijos. Mientras que la red familiar secundaria se refiere al contacto con tíos, primos, suegros, cuñados, sobrinos y padrinos con ahijados.
} 
Según este enfoque, las trayectorias biográficas se conforman a partir de un conjunto de transiciones “normativas” y "no normativas” que indican cambios de posición en el curso de la vida. Las transiciones construidas socialmente se convierten en "normativas" si son experimentadas por una gran proporción de la población, por ejemplo, el período de escolaridad, la entrada en el mercado laboral, la conformación familiar y el retiro (Elder, 1998, 1994). Aquellas transiciones que se perciben fuera de tiempo y entran en discordancia con lo establecido determinan un punto de inflexión o turning point.

Abonando a la perspectiva del curso de la vida, la viudez puede bien convertirse en un punto de inflexión en las trayectorias biográficas, generando cambios concretos como el abandono de actividades, la disminución del apoyo social y el incremento del sentimiento de soledad. A su vez, observamos que la literatura define a la viudez como una transición “típica” entre la tercera y la cuarta edad. Esto es, que constituye en términos demográficos una transición “esperable” pero que impacta en las biografías provocando una reconfiguración objetiva y subjetiva en la vida de las personas. Retomando el interrogante del inicio podemos sostener que la viudez es una transición esperable en el envejecimiento demográfico, sobre todo femenino, pero desde el punto de vista del envejecimiento individual, para las cohortes nacidas antes de 1950, se convierte en un punto de inflexión. Esto se debe a que el matrimonio con muchos años de convivencia se constituye como una institución que ordena los cursos de vida estándar y sigue la estructura "tripartita” de la vida donde la formación, el ingreso al mercado de trabajo y luego el retiro son subsidiarios a una configuración familiar “modelo” vigente hasta 1960, en pleno desarrollo del Estado de Bienestar (Kohli, 2007). Así, el curso de vida como "institución social” está marcado por la división de roles de género tanto en el ámbito doméstico como laboral. Desde este enfoque, el estudio de la viudez en el proceso de envejecimiento puede abordarse de acuerdo a los modos en que los varones y las mujeres mayores afrontan esta pérdida según sus cohortes de nacimiento.

Si bien el marco teórico y metodológico de este trabajo es el enfoque del curso de vida, el aporte de la perspectiva de género brinda algunas presiones útiles para comprender como la viudez es afrontada por esta cohorte de personas mayores. 
Los modos de afrontamiento de la viudez están influidos, sin duda, por la categoría género $^{7}$ entendida como una construcción cultural que se diferencia del determinismo biológico de los sexos sin desconocer la materialidad de esta diferencia (Lamas, 1996). En efecto, para la cohorte de personas entrevistadas nacidas entre 1930 y 1945 la construcción de los roles sociales está muy impregnada por el modelo de la subordinación de las mujeres hacia los varones (Miranda Novoa, 2012). En este punto, el curso de vida como institución social con un modelo tripartito (formación, trabajo y retiro) se erige y está pensado para consolidar lo que Kohli (2007) señala como una “biografía laboral normal” propia de los varones mientras que en el caso de las mujeres lo que se construye en paralelo es una “biografía familiar normal”. De este modo, la percepción de las normas y expectativas sociales asignadas a varones y mujeres, que se construyen basadas en la diferencia sexual, no generan contradicciones sino que se internalizan como "naturales” en los casos estudiados.

Recuperando estos aportes, el presente trabajo tiene por objetivo analizar cómo fueron vividos los cambios en la organización de la vida cotidiana, como fue percibido el apoyo social y cómo las mujeres y los varones entrevistados elaboraron el duelo. De este modo, la investigación apuntó a la identificación de similitudes y diferencias en torno a los roles sociales construidos en base a la diferencia sexual que estructuran el vínculo de pareja.

\section{Aspectos metodológicos}

Para dar curso al objetivo de la investigación se optó por un enfoque cualitativo que combinó elementos de dos perspectivas: a) componentes del enfoque biográfico (Kaufmann, 2008) y b) conceptos claves de la perspectiva del curso de vida (Elder, 1998). En este sentido nociones como transiciones, puntos de inflexión y biografía fueron útiles para analizar los modos en que se percibe y afronta la viudez.

El valor del enfoque biográfico radica en la multiplicidad de formas en que narrativamente se hace posible dialogar y comprender al otro/a. El espacio biográfico funciona, en este sentido, como un macro-género que a través de la entrevista permite el

\footnotetext{
${ }^{7}$ Género en este sentido no es equivalente al uso gramatical del castellano ni tampoco el reemplazo de "las mujeres". Se trata de una categoría que producto de una construcción social y cultural establece roles asignados en base a la diferencia biológica pasando de un modelo de subordinación de las mujeres respecto de los varones hacia uno de búsqueda de equidad jurídica.
} 
acceso a la vida íntima, a lo privado y a los sentimientos atribuidos a la experiencia de viudez en el proceso de envejecimiento. La posibilidad de comprender los significados que los actores expresan se funda en una interacción de naturaleza dialógica, comunicativa y fundamentalmente humana.

La entrevista en profundidad supone un encuentro cara a cara, que requiere del investigador/a la capacidad de escucha y “atención flotante” (Kaufmann, 2008). Se trata de una indagación no estructurada y creativa que facilita la expresión libre de pensamientos, ideas y sentimientos (Valles, 2000).

La entrevista en profundidad, se encuadra en el ámbito del espacio biográfico y supone, por un lado, un aspecto claramente diacrónico y, por otro, una dimensión sincrónica (Arfuch, 2002). La variante diacrónica se despliega en el espacio biográfico, permitiendo indagar cómo se han construido e interactúan las diferentes trayectorias (educativas, laborales y familiares) que constituyen la biografía de una persona. En cambio, en la dimensión sincrónica aportó datos acerca de los significados actuales atribuidos a la viudez.

El trabajo de campo reúne datos recabados entre abril de 2014 y diciembre de $2015^{8}$. La muestra fue de tipo intencional, conformada por 10 personas viudas de 65 y más años (5 varones y 5 mujeres); residentes en el Área Metropolitana de Buenos Aires y pertenecientes a diferentes niveles socio-económicos. Este trabajo se basa en una submuestra de 10 casos de un total de 19 personas entrevistadas. Dado que en su mayoría fueron viudas (5 varones y 14 mujeres) se eligieron mujeres con un amplio espectro en relación al tiempo que llevaban de viudez.

Durante un primer momento (4 meses) se realizaron entrevistas a profesionales del ámbito gerontológico que oficiaron de informantes claves y brindaron información relevante para el ajuste de la guía de entrevista. Las entrevistas, que constituyen las fuentes primarias de la investigación, se complementaron con datos secundarios provenientes de diferentes estudios, estadísticas y encuestas realizadas a la población de personas mayores residente en el Área Metropolitana de Buenos Aires, Argentina.

La búsqueda del perfil de viudas y viudas se realizó en diferentes instituciones (públicas, privadas y de ONG’s) a las que concurren personas mayores. Específicamente, se trató de dos centros de jubilados y una Asociación Mutual ubicados en el ámbito de la Ciudad de Buenos Aires, además de un centro de día para adultos

\footnotetext{
${ }^{8}$ Este trabajo forma parte del proyecto de investigación posdoctoral financiado por el Consejo Nacional de Investigaciones Científicas y Técnicas de la República Argentina (CONICET, 2014-2016).
} 
mayores y un centro residencial. En éstos últimos dos casos la ubicación geográfica fue la zona oeste y sur del Gran Buenos Aires. Se entrevistaron además viudos/as que no concurrían a instituciones a los fines de enriquecer la muestra. Para situar el contexto en el cual se desarrollaron las entrevistas se describen a continuación los datos sociodemográficos (ver Tabla 1).

Tabla 1: Caracterización de los participantes.

\begin{tabular}{|c|c|c|c|c|c|c|c|c|c|c|}
\hline Casos & Edad & $\begin{array}{l}\text { Tiempo } \\
\text { viudez }\end{array}$ & $\begin{array}{c}\text { Causa de } \\
\text { muerte } \\
\text { cónyuge } \\
\end{array}$ & $\begin{array}{l}\text { Vive } \\
\text { con... }\end{array}$ & $\begin{array}{c}\text { Cobertura } \\
\text { Previsional }^{1}\end{array}$ & $\begin{array}{l}\text { Atención de } \\
\text { Salud }^{3}\end{array}$ & $\begin{array}{c}\text { Nivel } \\
\text { educativo }\end{array}$ & Vivienda & ¿Trabaja? & $\begin{array}{c}\text { Hijos/a } \\
\text { s }\end{array}$ \\
\hline Bruno & 80 años & 6 años & $\begin{array}{l}\text { Cáncer de } \\
\text { colon }\end{array}$ & $\begin{array}{l}\text { Hija/ } \\
\text { Nietos }\end{array}$ & $\begin{array}{c}\text { Jubilación } \\
\text { Contributiva/ } \\
\text { Pensión } \\
\end{array}$ & $\mathrm{PAMI}^{4}$ & $\begin{array}{c}\text { Primario } \\
\text { Incompleto }\end{array}$ & Propia & No & 2 \\
\hline Cacho & 75 años & 13 años & $\begin{array}{l}\text { Cáncer de } \\
\text { huesos }\end{array}$ & $\begin{array}{c}\text { Hogar de } \\
\text { ancianos } \\
\text { privado } \\
\end{array}$ & $\begin{array}{c}\text { Jubilación } \\
\text { Contributiva }\end{array}$ & PAMI & Primario & Propia & No & 4 \\
\hline Antonio & 84 años & 24 años & Accidente & Hijos & $\begin{array}{c}\text { Jubilación } \\
\text { Contributiva }\end{array}$ & PAMI & Primario & Propia & No & 5 \\
\hline Armando & 81 años & 4 años & $\begin{array}{l}\text { Párkinson } \\
\text { Caída }\end{array}$ & Solo & $\begin{array}{c}\text { Jubilación } \\
\text { Contributiva/ } \\
\text { Pensión } \\
\end{array}$ & PAMI & Primario & Propia & No & 3 \\
\hline Jorge & 80 años & 7 años & $\begin{array}{c}\text { Enfermedad } \\
\text { degenerativa } \\
\text { de huesos } \\
\end{array}$ & Solo & $\begin{array}{c}\text { Jubilación } \\
\text { Contributiva/ } \\
\text { Pensión } \\
\end{array}$ & $\begin{array}{c}\text { PAMI/ } \\
\text { Hospital } \\
\text { Público } \\
\end{array}$ & Universitario & Alquilada & Sí & 2 \\
\hline Rosa & 83 años & 3 meses & $\begin{array}{c}\text { Enfermedad } \\
\text { de Alzhéimer }\end{array}$ & Nieto & $\begin{array}{c}\text { Jubilación ama } \\
\text { de casa }^{2}\end{array}$ & PAMI & Primario & Propia & No & 1 \\
\hline Irma & 71 años & 5 meses & $\begin{array}{c}\text { Cáncer } \\
\text { (leucemia) }\end{array}$ & Hija & $\begin{array}{c}\text { Jubilación ama } \\
\text { de casa/ } \\
\text { Pensión } \\
\end{array}$ & OSJERA $^{5}$ & Primario & Propia & No & 3 \\
\hline Ivanna & 78 años & 7 años & $\begin{array}{l}\text { Complicación } \\
\text { de úlcera }\end{array}$ & Sola & $\begin{array}{c}\text { Jubilación ama } \\
\text { de casa/ } \\
\text { Pensión } \\
\end{array}$ & PAMI & Primario & Propia & No & 3 \\
\hline Chuly & 72 años & 14 años & $\begin{array}{l}\text { Edema agudo } \\
\text { de Pulmón }\end{array}$ & $\begin{array}{l}\text { Hija/ } \\
\text { Nietos }\end{array}$ & Pensión & OSBA $^{6}$ & Primario & Propia & Sí & 1 \\
\hline Leonilda & 84 años & 21 años & $\begin{array}{l}\text { Afección } \\
\text { cardíaca }\end{array}$ & Hijo & $\begin{array}{c}\text { Jubilación ama } \\
\text { de casa }\end{array}$ & PAMI & $\begin{array}{c}\text { Primario } \\
\text { Incompleto }\end{array}$ & Propia & Sí & 2 \\
\hline
\end{tabular}

Fuente: Elaboración propia en base a los datos de la investigación. ${ }^{1}$ Las jubilaciones contributivas ordinarias son aquellas en las que se han aportado un total años formales (requeridos en cada régimen) en el mercado de trabajo, habitualmente 30 años. Las prestaciones no contributivas son aquellas a las que se accede cuando las personas se encuentran en situación de vulnerabilidad. Pueden contar con aportes que no cumplen con el tiempo exigido para acceder a una prestación contributiva o bien no contar con ningún aporte formal. ${ }^{2}$ La expresión Jubilación para Amas de Casa, se utiliza para denominar informalmente a una moratoria previsional que permite (en Argentina) a una persona comprar los años de servicios para acceder a una jubilación. Está dirigida a personas que nunca realizaron aportes, pero también se utiliza para comprar los años de servicios faltantes a quienes si bien, tienen aportes, no llegan a los requeridos por la legislación vigente para obtener la jubilación ${ }^{3}$ El sistema de salud argentino se divide en tres sectores: el sector de la seguridad social: constituida por todas las obras sociales incluida la obra social específica (PAMI); el sector privado, conformado por empresas de medicina prepagas y el sector público que abarca la atención en hospitales y centros de atención primaria entre otros establecimientos. ${ }^{4}$ PAMI - 
Instituto Nacional de Servicios Sociales para Jubilados y Pensionados. ${ }^{5}$ Obra Social de la Asociación del Personal del Agua y la Energía. ${ }^{6}$ Obra Social de la Ciudad de Buenos Aires.

La edad promedio fue de 78 años $^{9}$. Los años promedio de viudez fueron 10, siendo un poco menor entre las mujeres (8 años) y mayor entre los varones (11 años). Los entrevistados pertenecían a la cohorte nacida entre 1930 y 1945.

Del total de mujeres viudas, sólo una vivía sola mientras que el resto convivía con hijos/as o nietos. En el caso de los varones, sólo uno de ellos residía en un hogar de ancianos $^{10}$, el resto vivía solo aunque dos de ellos compartían el terreno de su vivienda con sus hijos.

Todas las personas entrevistadas cursaron estudios primarios de las cuales dos no alcanzaron a completarlos. Sólo una persona finalizó sus estudios secundarios y universitarios.

La cantidad de hijos promedio fue 2. Todos los entrevistados percibían algún beneficio previsional. Cinco recibían jubilación y pensión, el resto sólo pensión o jubilación. En cuatro casos accedieron a la jubilación no contributiva ${ }^{11}$. Tres personas continuaban trabajando además de recibir ingresos previsionales. Con respecto a la condición de actividad o inactividad de las personas mayores, en Argentina, es preciso aclarar que la edad jubilatoria es un criterio importante para valorar la distribución de la actividad de las personas mayores. En efecto, según datos provenientes del Programa de Investigación sobre la Sociedad Argentina Contemporánea (Pisac) dos tercios de la población mayor se considera inactiva siendo que un $89 \%$ de ellos son jubilados o pensionados, un $8,1 \%$ amas de casa y un 1,7\% corresponde a las personas con discapacidad (Oddone, 2018). El nivel de cobertura previsional en Argentina es elevado alcanzado un 92\%, no obstante, existe un déficit del 8\% en materia de acceso al empleo

\footnotetext{
${ }^{9}$ Entre los varones fue de 80 y de 77 años en las mujeres.

${ }^{10}$ En este caso fue él mismo quien decidió trasladarse a un geriátrico por sus problemas de movilidad, usa bastón y espera que lo operen de caderas para recuperar autonomía. Cacho (75 años) pasa sus jornadas diarias en un centro de día y duerme en un hogar de ancianos.

${ }^{11}$ En 1945 se constituyó el sistema nacional de la seguridad social con la activa participación del Estado. Los problemas de financiamiento a lo largo del tiempo llevaron a emprender una reforma en el año 1993, en un contexto de serias preocupaciones sobre la sustentabilidad fiscal en el mediano y largo plazo. El nuevo sistema introdujo un esquema financiero de capitalización individual y modificó la edad de retiro (pasando de 55 a 60 años para las mujeres y de 60 a 65 para los hombres) y la cantidad de años de contribución (pasando de 20 a 30 años). Estas medidas no mejoraron el nivel de cobertura por lo cual con el fin de corregir esa brecha se implementaron dos moratorias una en el año 2005 y otra en 2008, a través de las cuales se otorgó acceso a las prestaciones a la mayoría de los adultos mayores, independientemente de su historia contributiva previa. En 2008 se eliminó el régimen de capitalización y los trabajadores debieron cotizar al esquema de reparto administrado por el Estado.
} 
y la seguridad social en el grupo de personas mayores de 60 años según datos del Observatorio de la Deuda Social de la Argentina (Amadasi, 2017).

Desde una perspectiva regional, sin dejar de reconocer la reducción de los haberes previsionales debidos a la última reforma ${ }^{12}$, Argentina, junto con Brasil, Chile y Uruguay, es uno de los países denominados “pro-envejecimiento”, es decir, países con grandes sistemas de pensiones (Gragnolati et al., 2014).

En cuanto a la cobertura de salud en ocho de los diez casos utilizaban la obra social específica (PAMI-INSSJyP) ${ }^{13}$. El campo de la salud en Argentina ${ }^{14}$ se encuentra fragmentado entre el sector público, la seguridad social y el sector privado. Según datos del Programa de Investigación sobre la Sociedad Argentina Contemporánea (PISAC) el 45,8\% de las personas de 60 años y más cuenta con la cobertura de la obra social de los jubilados y pensionados (PAMI), el 38,7\% posee una obra social y el 5,8\% tiene una prepaga. Un 8\% de la población indica no tener cobertura por el sistema de la seguridad social, es decir, que cuenta con acceso al sistema público de salud. Observamos que esta tendencia a la utilización de la obra social específica (PAMI) es la que predomina en las personas entrevistadas. Otro dato que complementa el perfil sociodemográfico de los entrevistados es la propiedad de la vivienda en nueve de los diez casos estudiados ${ }^{15}$. El objetivo principal de la entrevista fue la reconstrucción de la trayectoria biográfica en el marco de una charla flexible y abierta. Los ejes temáticos abordados fueron los siguientes: historia de conformación y composición familiar, trayectoria laboral y educativa, estrategias de organización y gestión de la vida cotidiana, tipos y frecuencia de actividades realizadas, percepción del estado de salud, proyectos, concepciones de envejecimiento y apoyo social recibido. Se utilizó también la técnica de la síntesis vital que consiste en solicitar, a cada persona, un resumen biográfico en el que indique cuáles

\footnotetext{
${ }^{12}$ En 2017 se aprobó una nueva reforma previsional que entre sus principales puntos modificó la fórmula que se utilizaba para aumentar las jubilaciones (hasta ese momento dos veces al año en marzo y septiembre) a través de la llamada "ley de movilidad jubilatoria" (Ley 26417/2008). De este modo, se produjo una reducción de la jubilación promedio. A ello se sumó un decreto que permite ahora a los trabajadores jubilarse a los 70 años. Esta normativa prohíbe a las empresas intimar a jubilarse a las personas mayores de 65 años.

${ }^{13}$ Casi la totalidad de los entrevistados solicitaba el descuento en medicamentos que ofrece el PAMI.

${ }^{14}$ El sistema de salud argentino se desarrolló entre 1945 y 1955, en un período de crecimiento económico caracterizado por un proceso de industrialización, incremento de la urbanización y presencia activa de diferentes organizaciones sindicales. Durante los años siguientes se consolidaron tres grandes actores: el sector público, la seguridad social y el sector privado, con diferentes tipos de servicios, cobertura y fuente de financiamiento. Durante los años ' 80 y '90, se realizó un proceso de descentralización del sector salud desde el Nivel Central de Gobierno hacia los Gobiernos Provinciales

${ }^{15}$ El 84\% de la población de personas mayores en Argentina es propietaria de su vivienda según datos del Programa de Investigación sobre la Sociedad Argentina Contemporánea PISAC (Oddone 2018).
} 
fueron los momentos muy buenos, los no tan buenos y los períodos difíciles de su vida (Laborde, Lelièvre y Vivier, 2007).

En general, la duración de los encuentros fue de una a dos horas en los que se exploraron diversos aspectos a fin de reconstruir las trayectorias biográficas. La mayoría de las entrevistas se realizaron en una sola visita. La participación fue voluntaria y libre $\mathrm{y}$, en cada caso, se asumió el compromiso de proteger la identidad ${ }^{16}$.

Una vez efectuada la transcripción de las entrevistas, utilizando el método de comparación constante, se reconstruyeron las trayectorias identificando: temas principales, transiciones y puntos de inflexión (Strauss y Corbin, 2002). A continuación se compararon los datos primero de manera abierta, luego de manera más sistemática y, finalmente, se ponderaron las recurrencias y contrastes reagrupando las categorías que marcaban tendencias o patrones. De allí emergieron tres ejes que permitieron identificar similitudes y diferencias entre mujeres y varones. Para la reconstrucción de las biografías se utilizó un calendario de vida donde se consignaron años, edades, y diferentes dominios como salud, trabajo, educación y familia. Este instrumento permite tener una visión de conjunto de toda la biografía y ponderar el impacto de la viudez en el curso de la vida. El calendario de vida se realizó en base a la información obtenida en las entrevistas en profundidad (Laborde, Lelièvre y Vivier, 2007).

\section{La vida cotidiana después de la viudez}

En el caso de los varones la pérdida del cónyuge significó afrontar un largo período de cuidados, las hijas estuvieron especialmente presentes en estos momentos, a excepción de un caso en el que el cuidado fue asumido exclusivamente por el viudo ${ }^{17}$. Las causas de muerte fueron cáncer en dos casos, enfermedades degenerativas óseas y del sistema nervioso en otros dos casos y deterioro físico producto de un accidente vial en un único caso.

Es importe destacar que los años de convivencia con sus partenaires iban de 20 a 50. Este dato no es menor a la hora de analizar cómo impacta en las trayectorias la viudez.

\footnotetext{
${ }^{16}$ Se explicitó que la información recabada tenía exclusivamente fines académicos. Se respetó la posibilidad de interrumpir la entrevista cuando la persona lo deseara. Los aspectos mencionados se ajustan a la resolución $\mathrm{N}^{\circ} 2857$ (11 de Diciembre de 2006) sobre lineamientos para el comportamiento ético en las Ciencias Sociales y Humanidades destinados a los investigadores del Consejo Nacional de Investigaciones Científicas y Técnicas de la República Argentina.

${ }^{17}$ En algunos casos se recurrió además a la contratación de cuidadores domiciliarios.
} 
Todos los viudos entrevistados concurrían a algún tipo de institución donde realizaban actividades socio-preventivas y recreativas (centro de día, centro de jubilados o asociación mutual). La concurrencia a estos establecimientos fue siempre posterior a la viudez buscando paliar la soledad y el aburrimiento.

Cabe aclarar que la población de estos centros destinados a mayores es mayormente femenina, es decir, que estos varones viudos representan una pequeña porción poblacional (ENCaViAM, 2012). Siguiendo la tendencia masculina que indica la literatura, los viudos entrevistados expresaron su intención de encontrar una nueva compañera (SánchezVera, 2009).

En cuanto a los cambios en la vida cotidiana se observó que ocurrieron fundamentalmente en dos planos:

a) Actividades que se realizan en soledad como comer, dormir, tomar mate o despertarse.

(...)Y la compañía nada más, eso es, la soledad es muy fea. Usted toma mate solo, come solo, es un decir no es cierto, no es lo mismo. Duerme solo, se despierta y está solo, es una cosa que uno sabe cuando vive esa parte, porque usted no se imagina lo que es (Bruno, 80 años, 6 años de viudez).

b) Actividades recreativas que se abandonaron como viajar, salir a pasear, ir al teatro o vacacionar.

(...) íbamos mucho a veranear con Amalia a ella lo que más le gustaba era Piriápolis, en el Hotel Argentino fuimos como siete veces; le gustaba muchísimo. Tengo películas filmadas porque apenas nos casamos me regaló una filmadora y tengo como 100 películas filmadas de todos los veraneos. Eso lo extraño ahora (Armando, 81 años, 4 años de viudez).

Las mujeres viudas perdieron a sus cónyuges a causa de enfermedades que implicaron un período de cuidados en tres de los cinco casos, mientras que dos de ellas sufrieron la muerte repentina de sus esposos. Las causas fueron: una enfermedad neurodegenerativa (Alzheimer), cáncer (leucemia) y la complicación de una úlcera. Las muertes repentinas se debieron a un paro cardíaco y a un edema agudo de pulmón.

Los cuidados fueron asumidos por ellas y, en algunos casos, recibían también ayuda de sus hijas. Los años de convivencia superaban los 30 en cuatro de los cinco casos ${ }^{18}$. Observamos que, tanto para las mujeres como para los varones, se trató en general de matrimonios de larga data. Las mujeres viudas convivían con sus hijos, hijas y/o nietos en cuatro de los cinco casos. A este respecto encontramos diferencias en relación a los

\footnotetext{
${ }^{18}$ Sólo en un caso la convivencia fue de 7 años. Esta menor cantidad de años se debió a que se trataba de un matrimonio constituido en segundas nupcias.
} 
varones que vivían solos. Ninguna de las mujeres expresó deseos de conseguir una pareja. Sólo en un caso había existido una relación sentimental luego de la viudez que no perduró. Cabe también destacar que las viudas entrevistadas, salvo en un caso, no asistían a instituciones socio-recreativas para mayores. Las mujeres encontraban contención emocional y material en sus hermanas, hermanos, cuñadas, hijas y nietos que conformaban sus redes más significativas.

Los cambios en la vida cotidiana de las viudas tuvieron que ver con:

a) Actividades como cuidar la quinta y/o reparar, refaccionar y mantener la vivienda.

(...)éramos compañeros. Iba arriba hacía cosas, venía y me decía: qué querés que haga y yo le daba trabajo. Como él lo sabía hacer todo, vos le decías ¡uy! ¿me podés hacer esto para la plantita? y lo hacía... [se emociona] y cuando él se vio enfermo... y bueno...[hace una pausa].Y bueno, él hacía todo. Esto lo hizo Sergio [su hijo] viste y mi marido, se daba maña para todo, acá no entró ni un albañil ni nadie (Irma, 71 años, 5 meses de viudez).

b) Actividades recreativas que se abandonaron como viajar, vacacionar, pasear o mirar películas.

(...) Sí por ejemplo el domingo, sábado y domingo con el coche, teníamos coche en aquél entonces, nos íbamos a tomar mate si era por acá cerca ¿no? Y si no, íbamos a visitar a la familia también pero no, en casa los días de feriado se iba a pasear; ahora me quedo porque ¿qué sé yo? estoy sola (Leonilda, 84 años, 14 años de viudez).

Las diferencias tuvieron que ver con roles que se ordenan de acuerdo al género. Esto es, mujeres identificadas con las tareas domésticas y varones asumiendo la manutención y refacción de la vivienda. En cambio, en lo que respecta a las actividades recreativas fueron añoradas tanto por los viudos como por las viudas.

\section{EI apoyo social percibido}

En el análisis se tuvieron en cuenta 4 tipos de apoyos sociales según las funciones desempeñadas.

a) El apoyo afectivo está referido a las expresiones de afecto y cariño que implican contacto físico como abrazos y besos. Este tipo de apoyo es el que se ve mermado a partir de la viudez y es el que más impacta a nivel subjetivo.

Los varones entrevistados expresaron, a excepción de un caso, su deseo de volver a tener pareja para, además de satisfacer deseos afectivos y sexuales, disfrutar de la compañía en las actividades de la vida cotidiana. En efecto, dos de los varones entrevistados estaban iniciando una relación de pareja en la que proyectaban expectativas positivas. 
(...) Porque como ahora estoy recuperando mi actividad sexual ya pienso en tener una compañera. (...). Salir, ir a un concierto, yo he sido concurrente del Colón, a mí la música clásica me enloquece y soy de ir al cine al teatro (Jorge, 80 años, 7 años de viudez).

Las mujeres mencionaron a sus hijos o hijas como las personas que brindan apoyo afectivo en términos de contacto físico. Dos de las viudas estaban elaborando el duelo por la pérdida ocurrida apenas unos meses antes de la entrevista. No hubo menciones acerca de deseos sexuales o falta de contacto físico como sí lo hicieron en mayor medida los viudos.

E: Como dador de afecto y contacto físico, abrazos etc. ¿A quién ubicaría en ese rol?

I: Ah, bueno, yo tengo a los tres hijos, a los tres porque yo si llamé a uno y al otro no se ponen celosos. Si necesito tengo (Irma, 71 años, 5 meses de viudez).

b) El apoyo emocional supone la posibilidad de contar con personas en quienes poder confiar, a quienes acudir frente a un problema para pedir y recibir consejos y, esencialmente, con quienes sentirse contenido. Los varones sólo en un caso mencionaron a los amigos como las personas que desempeñaban estas funciones. Otros dos viudos afirmaron no contar con nadie y los dos restantes contaban con algunos de sus hijos a la hora de requerir consejo y contención.

(...) No, no tengo, yo me descargo solo. Ya te digo es una experiencia muy linda, hay gente que acá que se han descargado en mí, mucha gente. Cuántas veces, Cacho me pasa esto, el otro, son muchachos que se han criado adentro de un cuartel, no saben nada de la vida de afuera. Yo les digo las cosas son así, asá, la calle es distinta y como esos unos cuantos viste. Pero yo, descargarme en alguien no (Cacho, 75 años, 13 años de viudez).

Las mujeres, en cambio, afirmaron tener personas en quienes poder confiar como hermanas, cuñadas e hijas y, en menor medida, amigas. Las hermanas mujeres y las cuñadas fueron las figuras más importantes en cuanto a este tipo de apoyo.

(...) Bueno, consejos justamente lo hago con esta cuñada que ya te digo (...) a veces no puede hablar mucho porque se fatiga porque es asmática. Siempre me orientó bien, siempre me dio consejos buenos (Chuly, 72 años, 21 años de viudez).

c) El apoyo material e instrumental implica poder recibir asistencia en la vida cotidiana con las tareas domésticas, durante un proceso de enfermedad o contar con compañía en una visita al médico. El apoyo instrumental puede ser también económico. Estas ayudas en el caso de las personas mayores son más frecuentes debido al incremento de la fragilidad en la vejez.

Los varones contaban con sus hijos o hijas en una situación de enfermedad. También algunos de ellos recurría a sus hijos para realizar controles médicos, no obstante, el deseo genuino era de "no molestarlos”. Esta sensación de estar importunando la vida de los hijos fue muy marcada en el caso de los viudos. El sentimiento que domina es el de 
distancia, lo que sugiere que las personas se perciben así mismas en otra posición del curso de la vida. Así, la muerte se vislumbra más cercana y la amenaza de la dependencia resulta muy angustiante.

(...) Los años empiezan a pesar y los hijos no... no es que no le puedan cuidar es que tienen sus compromisos. Tienen su esposa, sus hijos y ahora vienen más grandes, tienen que hacerlos estudiar y uno ya está medio que no tiene que estar. Por más que ellos digan que no les molesta, uno está molestando sí. Porque yo tengo ochenta años y ellos tienen cuarenta. Hay cuarenta años de diferencia, es muy distinta la vida que hice yo con la que ellas están haciendo ahora (Bruno, 80 años, 6 años de viudez).

Dos de los viudos, que pertenecen a un sector socioeconómico medio, contaban con personal doméstico que los asistía en las tareas de limpieza. Cocinar era una de las tareas que presentaba más dificultad para los varones viudos, cuatro de ellos concurrían a centros de día donde compartían dos comidas diarias, con lo cual estas instituciones cumplían parte de este apoyo diario.

Las mujeres recibían apoyo instrumental generalmente de parte de otras mujeres, nietas, hijas y nueras. Los hijos varones brindaban apoyo económico en algún caso. Rosa (80 años), por ejemplo, cuenta con tres de sus nietas, que se turnan para ordenar y controlar su medicación, hacer gestiones en la obra social o acompañarla al médico.

R: Voy con ella [su nieta], que se encarga de ir a PAMI, se encarga de irme a buscar los remedios como se encargó estos días. Mirá, acá tengo el pastillero que ella viene y me prepara todos los remedios que tengo que tomar por día. Ahora puede aparecer en cualquier momento y vuelve a llenarme el pastillero. Y cuando no los tomo me tira la bronca (Rosa, 80 años, 3 meses de viudez).

d) Un último apoyo lo conforman las relaciones sociales de ocio y distracción cuyo objetivo es pasar un momento de distención y diversión mientras se comparten actividades recreativas o lúdicas. Los viudos contaban con este tipo de apoyo, ya sea por asistencia a un centro de jubilados, centro de día o asociación mutual. Los tipos de actividades que realizaban eran variadas: lúdicas (truco, tejo, etc.), recreativas (estimulación de la memoria, canto, salidas grupales, dibujo, radio, taller de escritura) y físicas (baile, gimnasia, tai-chi, etc.).

(...) juego al tejo pero no vienen nunca estos muchachones que encontré trece cuando llegué, hoy jugaron. Tejo, truco y baile, yo bailo el tango de salón. Y ya te digo, el otro día bailé con una señora que al final resultó ser la dueña de la estancia y me aplaudieron mucho, la gente me aplaudió mucho (Armando, 81 años, 4 años de viudez).

En el caso de las viudas, las relaciones de ocio y distracción fueron muy pocas. La excepción es el caso de Chuly (72 años) que luego de enviudar aseguró que concurrir al centro de jubilados le cambió la vida. Ella toma clases de folklore y los fines de semana frecuenta las peñas con amigas. Encontramos aquí una diferencia con los viudos que, 
probablemente, se deba al fuerte apoyo de las redes familiares que perciben las mujeres lo que las lleva a demandar menos relaciones de ocio.

\section{La experiencia de soledad}

Hemos analizado como es percibido el apoyo por los viudos donde las expresiones de cariño son la falta más mencionada. Esto se acompaña de un gran sentimiento de soledad. La experiencia de soledad subjetiva se define como ausencia de afecto y compañía de la persona deseada, situación que provoca malestar y angustia y que se diferencia de la soledad social o aislamiento, definido como la ausencia objetiva de compañía (Flores, 1986). Existen diferencias a nivel de las percepciones masculinas y femeninas de la soledad. Los varones afirmaron que "es más fácil para las mujeres” porque tienen más facilidad para comunicarse y establecer nuevos vínculos. Esto se refleja en los quehaceres diarios como comer o dormir y en las actividades que se abandonaron como viajar, pasear o vacacionar.

La soledad se siente más por la noche como bien lo describe Antonio (84 años) quien elige distraerse con la radio y la televisión. La decisión de asistir a una institución, para realizar actividades o distraerse, fue una estrategia para reducir la experiencia subjetiva de soledad. Los fines de semana son más difíciles de "llenar", algunos de ellos visitan a sus hijos/as o simplemente salen para no permanecer solos mucho tiempo.

(...) Cuando uno más se acuerda es de noche cuando se acuesta, como uno está solo. Yo cuando empiezo a pensar algo que no me gusta prendo la tele, soy flojo para ver la tele, estando acostado me quedo dormido enseguida. Cuando me despierto siempre hay alguien que habla, la tele o la radio también. La radio la tengo acá y la tele enfrente y pasa así (Antonio, 84 años, 24 años de viudez).

Las mujeres viudas mencionaron menos el sentimiento de soledad, quizá porque la compañía cotidiana de sus hijas y nietas, sobre todo, disminuye los momentos en que la soledad se siente más. El hecho de convivir con otros marca ya una diferencia flagrante entre varones y mujeres.

(...) Como me siento, me siento bien porque vos imaginate a mí no me falta nada. En el sentido, tengo los hijos, están siempre los tres. Y Eli [la hija que vive con ella] que yo quisiera que ella tenía tantas cosas en su mente y ahora capaz que cambia. Yo quisiera que ella haga su vida y yo es diferente, ya está la mía. Pero estoy bien (Irma, 71 años, 5 meses de viudez).

\section{EI proceso de duelo}

El duelo implica una sucesión de fases o tareas dirigidas a reconstruir el mundo sin la persona, el objeto o la función perdida (Molinié, 2006; Freud, 1917). Según el esquema 
de Worden (1997) la primera de esas tareas consiste en la aceptación de la pérdida, esos primeros momentos están dominados por el shock, la angustia y la negación. Las siguientes tareas suponen poder dar sentido a los sentimientos asociados a la pérdida, previendo la posibilidad de integrarlos a la propia biografía. Esta fase se encuentra dominada por la desolación, la tristeza, la resignación y, finalmente, la aceptación. Luego se trata de poder resolver las tareas antes realizadas por la persona fallecida. Por último, se produce una reconexión con el mundo externo donde se reorientan hacia otros destinos los sentimientos antes dirigidos hacia la persona.

Con respecto al proceso de duelo, en el caso de los varones, no existieron muertes repentinas o trágicas que impidieran la elaboración de la pérdida. Los entrevistados destacaron que los dos años posteriores fueron muy “duros”. La muerte de la mujer constituye un punto de inflexión que delimita un antes y un después en todos los casos. En el caso de Jorge (80 años) al poco tiempo del fallecimiento de su esposa, se le diagnosticó un cáncer de próstata por el que fue tratado y del que logró recuperarse. A ello se sumó un estado depresivo que lo acompañó en los primeros dos años de viudez. Por su parte, Cacho (75 años) afirmó que su “vida quedó ahí” que simplemente una vez fallecida su esposa "sobrevivió”.

(...) Fueron cuatro cinco años pero después se enfermó y se fue todo a la mierda [sic], se fue todo al demonio. Estuve dos años con ella en una batalla que sabías que ibas a perder viste y se fue, después quedé solo. Es un círculo del que hasta el día de hoy no salí, pero en mi vida privada sigo, pero la parte de mi vida quedó ahí. Una vez que murió mi mujer sobreviví como quien dice (Cacho, 75 años, 13 años de viudez).

El tipo de vínculo construido con la pareja es un factor clave en el proceso de duelo. Los varones viudos han definido sus relaciones conyugales de manera positiva, donde los roles estaban consensuados y la reciprocidad estructuraba el vínculo. De allí que el impacto resultara muy estresante y difícil de elaborar.

En dos casos las mujeres viudas se encontraban transitando la fase donde domina la tristeza y la resignación debido a la pérdida reciente del cónyuge. Las expresiones emocionales y el silencio provocaron algunos quiebres durante la entrevista en estos casos. No obstante, a pesar del impacto que provoca la viudez, las mujeres afirmaron sentirse acompañadas por sus familias. Esta contención les permitía reorganizar su vida y su mundo sin el ser querido.

Cuando se trató de muertes repentinas el proceso de duelo estuvo asociado a padecimientos emocionales como la depresión. Leonilda (84 años) aseguró que los años posteriores fueron duros, llenos de tristeza que la llevaban a no querer levantarse de la 
cama y a no tener ganas de comer, ni deseos de nada. Luego pudo reponerse y lleva ya 14 años de viudez.

(...) Y sí; yo no me resignaba, no, que Daniel, el mayor me decía: 'No te enojes con Dios' no ¿qué me voy a enojar con Dios? El destino de él fue ese. No tenía ganas de comer, así no era vida, no, mi hijo venía y me encontraba así en un sillón o en la cama. Y no era vida para mí porque no me hallaba (Leonilda, 84 años, 14 años de viudez).

En el caso de Chuly (72 años) el impacto que le generó la muerte inesperada de su último esposo, reactivó el duelo por la pérdida temprana de su padre. Esta situación desembocó en un estado depresivo por el cual recibió tratamiento psiquiátrico pero “pudo salir” y lleva ya 21 años viviendo sin su esposo.

Es interesante notar que en uno de los cuatro casos femeninos la viudez representó una suerte de liberación. Con un poco de pudor, Ivanna, una inmigrante eslovena de 78 años, me confesó que le fue infiel a su esposo con el consentimiento de él puesto que le daba mucha "libertad"19. Se casó para satisfacer una demanda de su hermana y "lloró de tristeza el día de su casamiento por civil”. Su matrimonio no fue feliz y sus únicos momentos de plenitud fueron los nacimientos de sus tres hijos, especialmente, el de su hija mayor.

(...) Ah, mi marido para qué, entonces uno estaba sola acá extranjera ¿no? No sabe las costumbres de acá, paisanos siempre había y uno lo trajo, paisano. Dice: bueno acá tenés una paisana y yo le conocí toda su familia del pueblo, acá tenés una paisana que pueden ustedes llegar a relacionarse.Entonces apareció él no me gustó, no me gustó y a lo último le dije mirá mejor nosotros no nos casamos, entonces se fue.Después volvió entonces había que casarse sí o sí. Bueno y el día que yo me casé por civil yo lloré todo el camino en el coche. Y no lloré de alegría, lloré de tristeza que me iba a casar con él y así, como no soy nada conformista y soy muy exigente. Toda la vida yo no quería eso, aparte podíamos arreglarnos nosotros, porque si él podía ser más simpático pero era un hombre serio. Para mí era mi padre (Ivanna, 78 años, 7 años de viudez).

Con respecto al proceso de duelo, observamos que no existen marcadas diferencias entre mujeres y varones. Sin embargo, lo que sí seadviertees que la elaboración de la pérdida se encuentra modelada por el nivel de apoyo percibido, que fue mucho más significativo en el caso de las mujeres y no tanto en el de los varones.

\section{La viudez en perspectiva...}

\footnotetext{
${ }^{19}$ Según la tipología realizada en un estudio con mujeres viudas en Chile, esta tendencia se corresponde con la "viudez comodespliegue" donde se valora positivamente liberarse del control marital vivido como una carga, opuesta a la "viudez comoorfandad" donde lo que se resiente la desprotección material y social (Del Pozo y Thumala Dockendorff, 2016).
} 
Hemos visto hasta aquí cómo la viudez repercute en todas las áreas de la vida. Así, la salud, la identidad y las relaciones sociales pueden verse resentidas al perder al cónyuge en la vejez. A modo de conclusión podemos identificar una serie de diferencias y similitudes en la manera en que la viudez es vivida por varones y mujeres.

En la vida cotidiana las diferencias tuvieron que ver, en el caso de los viudos, con las actividades que hacen a la satisfacción de necesidades diarias como, por ejemplo, cocinar. Las viudas, en cambio, notaban la falta del cónyuge en lo que atañe a la refacción y reparación de la vivienda. En tanto que las actividades recreativas que se abandonaron fueron mencionadas tanto por varones como por mujeres. Esta división según roles de género fue también encontrada en otras investigaciones sobre el tema (Pochintesta, 2016, 2013; Colombo et al., 2014; Sánchez-Vera, 2009).

El apoyo social también fue percibido de modo diverso por mujeres y varones. En efecto, la falta de apoyo afectivo y, sobre todo, físico, fue más marcada para los viudos así como lo fue el deseo de buscar y concretar una nueva pareja. Por el contrario las viudas no mencionaron este tipo de apoyo. Las mujeres afirmaron contar con mucho más apoyo emocional, por parte de otras mujeres (hermanas, cuñadas e hijas) que los varones para quienes casi no existían personas que desempeñaran estas funciones. En este mismo sentido, las viudas aseguraron recibir apoyo instrumental de parte de sus hijos, hijas y nietos con mucha mayor frecuencia que los viudos. Los varones contaban con sus hijos pero evitaban recurrir a ellos para no asediarlos con sus demandas. Otra diferencia a nivel del apoyo percibido ocurría en el caso de las relaciones de ocio y distracción, siendo los viudos quienes realizaban una gran cantidad de actividades en ámbitos institucionales, a diferencia de las viudas que no tenían relaciones de este tipo. Otras investigaciones muestran resultados análogos sobre la diferencia de género en el apoyo social percibido (Ayuso, 2012; Anderson, 1984).

El sentimiento de soledad subjetiva fue mucho más marcado en el caso de los viudos que de las viudas. Este aspecto ha sido también destacado en la investigación de Sánchez-Vera (2009) sobre la viudez en España. En la síntesis de vida realizada por los entrevistados, la muerte del cónyuge marcó un antes y un después en las trayectorias. No obstante, las mujeres parecen sobrellevar mejor la soledad que los varones y sentirse más acompañadas. Es decir que, el impacto de la viudez femenina está morigerado por otras mujeres que conforman redes de enorme importancia. La viudez masculina en 
cambio se vive mucho más en soledad. Esto se debe en parte a la construcción de la subjetividad asociada a los roles de género (Askham, 1996).

En cuanto al proceso de duelo hay que diferenciar dos factores que influyen en la elaboración de la pérdida. Primero el tipo de vínculo construido y luego las circunstancias de la muerte. Los viudos definieron vínculos de reciprocidad equilibrados que llevaban de 20 a casi 50 años de convivencia y en ningún caso hubo muertes repentinas. Las viudas también describieron vínculos poco conflictivos con convivencias que fueron desde los 7 a los 30 años. En un sólo caso, en que el matrimonio fue forzado, la viudez no significó un punto de inflexión. Las muertes repentinas de los cónyuges afectaron en dos casos el proceso de duelo. Un punto común mencionado por mujeres y varones fueron las afecciones psíquicas y orgánicas secundarias a la pérdida (depresión y cáncer).

Las mujeres entrevistadas están mejor preparadas para afrontar la viudez desde el punto de vista relacional debido a que cuentan, en general, con sus familias como principal fuente de apoyo. Desde el punto de vista económico se encuentran más desprotegidas, sobre todo aquellas que no han logrado una independencia económica.

Por último, retomando la perspectiva del curso de vida, podemos afirmar que la viudez en el envejecimiento constituye un punto de inflexión que se encuentra modelado por los roles de género en la cohorte ${ }^{20}$ de las personas entrevistadas.

\section{Referencias}

AMADASI, Enrique. Las condiciones de salud de las personas mayores. Sus aspectos más críticos Enrique Amadasi; Cecilia Tinoboras. Ciudad Autónoma de Buenos Aires: Educa, 2017.

ANDERSON, Trudy B. Widowhood as a lifetransition: Itsimpactonkinshipties. Journal of Marriage and theFamily, p. 105-114, 1984.

ARBER, Sara; GINN, Jay. Relación entre género y envejecimiento: enfoque sociológico. Madrid: Narcea Ediciones, 1996.

ARFUCH, Leonor. El espacio biográfico: dilemas de la subjetividad contemporánea. Buenos Aires: Fondo de cultura económica, 2002.

${ }^{20}(1930-1945)$. 
ASKHAM, Janet. Vida matrimonial de las personas mayores. En: ARBER, Sara y GINN, Jay. (Comp.) Relación entre género y envejecimiento. Enfoque sociológico. Madrid: Narcea, pp.127-140,1996.

AYUSO, Luis. Las redes personales de apoyo en la viudedad en España/Personal Networks SupportingWidowhood in Spain. Reis, p. 3-24, 2012.

BEAL, Claudia. Loneliness in older women: a review of the literature. Issues in Mental Health Nursing, vol. 27, $\mathrm{n}^{\circ}$ 7, p. 795-813, 2006.

BERGER, KathleenStassen. Psicología del desarrollo: adultez y vejez. Ed. MédicaPanamericana, 2009.

CARADEC, Vincent. Les transitions biographiques, étapes du vieillissement. Prévenir, vol. 35, no 2, p. 131-137, 1998.

CARR, Deborah. Gender, preloss marital dependence, and older adults' adjustment to widowhood. Journal of Marriage and Family, vol. 66, nº 1, p. 220-235, 2004.

COLOMBO, Viviana X. Lasagni, et al. Viudez y Vejez en América Latina. RevistaKairós: Gerontologia, vol. 17, n 1, p. 9-26, 2014.

CONSEJO NACIONAL DE INVESTIGACIONES CIENTÍFICAS Y TÉCNICAS. Lineamientos para el comportamiento ético en las Ciencias Sociales y Humanidades, Resolución $N^{o}$ 2857. Buenos Aires: Consejo Nacional de Investigaciones Científicas y Técnicas, 2006. Disponible en: http://web.conicet.gov.ar/documents/11716/0/RD+20061211-2857.pdf

[Recuperado el 10 de Mayo de 2017].

DEL POZO, Marisol T.; THUMALA DOCKENDORFF, Daniela. Reconstrucción de soportes sociales en mujeres urbanos populares post viudez: Una mirada a los cuidados. Psicoperspectivas, vol. 15, nº 3, p. 78-86, 2016.

DELBÈS, Christiane; GAYMU, Joelle. Le choc du veuvage à l'orée de la vieillesse: vécusmasculin et féminin. Population, vol. 57, nº 6, p. 879-909, 2002.

DOBLAS, Juan López; CONDE, María del Pilar Díaz; MARTÍNEZ, Mariano Sánchez. El rechazo de las mujeres mayores viudas a volverse a emparejar: cuestión de género y cambio social. Política y Sociedad, Vol. 51 nº p. 507-533, 2014.

ELDER JR, Glen H. Time, human agency, and social change: Perspectives on the life course. Social psychologyquarterly, p. 4-15,1994.

ELDER JR, Glen H.The life course as developmental theory. Child development, vol. 69, $\mathrm{n}^{\circ}$ 1, p. 1-12, 1998. 
ENCUESTA NACIONAL SOBRE CALIDAD DE VIDA DE ADULTOS MAYORES.

Ciudad Autónoma de Buenos Aires: Instituto Nacional de Estadística y Censos INDEC, 2014. E-Book, 2012.

FLORES, A. Aspectos gerontológicos de la soledad. Revista Española de Geriatría y Gerontología, vol. 21, p. 181-187, 1986.

FREUD, Sigmund. Duelo y melancolía. En: Obras completas, Tomo XIV. Argentina: Amorrortu, pp. 241-257, [1917]1992.

GILLEN, Martie; KIM, Hyungsoo. Older women and poverty transition: Consequences of income source changes from widowhood. Journal of Applied Gerontology, vol. 28, n 3, p. 320-341, 2009.

GRAGNOLATI, Michele, ROFMAN, Rafael, APELLA, Ignacio y TROIANO, Sara. Los años no vienen solos. Oportunidades y desafíos económicos de la transición demográfica en Argentina. Uruguay: Banco Mundial, 2014.

GUZMÁN, José Miguel, et al. La démographie de l'Amérique latine et de la Caraïbedepuis 1950. Population, vol. 61, nº 5, p. 623-733, 2006.

HA, Jung-Hwa, et al. Older adults' perceptions of intergenerational support after widowhood: How do men and women differ?. Journal of Family Issues, vol. 27, $\mathrm{n}^{\circ}$ 1, p. 3-30, 2006.

HAGEDOORN, Mariet, et al. Does marriage protect older people from distress? The role of equity and recency of bereavement. Psychology and aging, vol. 21, $\mathrm{n}^{\mathrm{o}} 3$, p. 611, 2006.

HAREVEN, Tamara. Life course.In:BIRREN, James. E. (ed.) Encyclopedia of Gerontology .San Diego: AcademicPress, pp. 31-40, 1996.

INSTITUTO NACIONAL DE ESTADÍSTICAS Y CENSOS. Censo Nacional de Población, Hogares y Viviendas, 2010. Disponible en: http://www.censo2010.indec.gov.ar (Recuperado el 20 de Noviembre de 2017).

KAUFMANN, Jean-Claude. L'entretiencompréhensif. Paris Armand Colin, 2008.

KOHLI, Martin. The institutionalization of the life course: Looking back to look ahead. Research in human development, vol. 4, n 3-4, p. 253-271, 2007.

LABORDE, Caroline; LELIÈVRE, Éva; VIVIER, Géraldine.Trajectoires et événementsmarquants, comment dire sa vie?. Population, vol. 62, nº 3, p. 567585, 2007. 
LALIVE D’EPINAY, Christian et al. El curso de la vida: la emergencia de un paradigma interdisciplinario. En: YUNI, José Antonio (Comp.) La vejez en el curso de la vida. Córdoba: Encuentro Grupo Editor, pp.11-30, 2011.

LAMAS, Marta. El género. La construcción cultural de la diferencia sexual, 1996.

LOPATA, Helena Znaniecki. Self-identity in marriage and widowhood. The Sociological Quarterly, vol. 14, nº 3, p. 407-418, 1973.

MOLINIÉ, Magali. Soigner les morts pour guérir les vivants. Paris : Le Seuil, 2006.

MOORMAN, Sara M.; BOOTH, Alan; FINGERMAN, Karen L. Women’s romantic relationships after widowhood. Journal of Family Issues, vol. 27, nº 9, p. 12811304, 2006.

NOVOA, Martha Miranda. Diferencia entre la perspectiva de género y la ideología de género. Díkaion: revista de actualidad jurídica, vol. 21, nº 2, p. 337-356. 2012.

ODDONE, María Julieta. Condiciones de vida de las personas mayores. En: Piovani, J.I. y Salvia, A. (Coords.) La Argentina en el Siglo XXI cómo vivimos y convivimos en una sociedad desigual. Encuesta Nacional sobre la Estructura Social. Buenos Aires: Siglo XXI Editores, p. 593-623, 2018.

OSORIO-PARRAGUEZ, Paulina. Health and widowhood: Meanings and experience of elderly women in Chile. Health, vol. 5, nº 08, p. 1272-1276, 2013.

POCHINTESTA, Paula A. (2013).Construcción social de la muerte en el envejecimiento. Un análisis de las representaciones de la muerte y su influencia como punto de inflexión en el curso de la vida. Universidad de Buenos Aires, Tesis Doctoral (Inédito).

POCHINTESTA, Paula A. La transición a la viudez en el envejecimiento. Un estudio de casos en Argentina. Journal of Aging \& Innovation, vol. 5, n 2, p. 4-19, 2016.

SÁNCHEZ VERA, Pedro. Viudedad y vejez. Estrategias de adaptación a la viudedad de las personas mayores en España. Valencia: NauLlibres-Edicions Culturals Valencianes, 2009.

STRAUSS, Anselm L.; CORBIN, Juliet. Bases de la investigación cualitativa: técnicas y procedimientos para desarrollar la teoría fundamentada. Medellín: Universidad de Antioquia, [1990] 2002. 
UTZ, Rebecca L., et al. The effect of widowhood on older adults' social participation: An evaluation of activity, disengagement, and continuity theories. The Gerontologist, vol. 42, nº 4, p. 522-533, 2002.

VALLES, Miguel S. Técnicas cualitativas de investigación social. Sintesis Editorial, 2000.

WORDEN, William J. El tratamiento del duelo: asesoramiento psicológico y terapia. Buenos Aires: Paidos, 1997.

Recebido 23/04/2019

Aprovado 28/05/2019 